\title{
Systematic Dynamic Modeling of an Integrated Single-stage Power Converter
}

\author{
Ki-Young Choi*, Kui-Jun Lee**, Yong-Wook Kim* and Rae-Young Kim ${ }^{\dagger}$
}

\begin{abstract}
This paper proposes a novel systematic modeling approach for an integrated single-stage power converter in order to predict its dynamic characteristics. The basic strategy of the proposed modeling is substituting the internal converters with an equivalent current source, and then deriving the dynamic equations under a standalone operation using the state-space averaging technique. The proposed approach provides an intuitive modeling solution and simplified mathematical process with accurate dynamic prediction. The simulation and experimental results by using an integrated boostflyback converter prototype provide verification consistent with theoretical expectations.
\end{abstract}

Keywords: Integrated single-stage power converter, Systematic modeling, State-space averaging, Small-signal model, Dynamic equation

\section{Introduction}

For low cost, high efficiency, and high performance, integrated power converter topology that incorporates a multi-stage power converter into an equivalent single-stage has been extensively researched [1-4]. One typical example is the integrated boost (or buck) flyback converter (IBFC) for $\mathrm{dc}$-dc conversion, electronic ballast, and power-factorcorrected power supply application.

As shown in Fig. 1, the IBFC integrates two single converters: a boost (or buck) converter and a flyback converter under a cascade configuration, into a single-stage configuration with a shared main switch, $S_{1}$, and a dc-link capacitor, $C_{e}$. As a result of topological integration, the IBFC provides several advantages over a conventional multi-stage converter, including reduced size, weight, and cost, and better power conversion efficiency [2, 15]. Moreover, the control performances, such as the inputcurrent shaping, isolation, and fast output regulation, can be improved by a proper single feedback compensator design that includes accurate prediction of the IBFC's dynamic behaviors $[5,6]$. However, the prediction of these behaviors, which is essential to guarantee the compensator's dynamic performance and stability, is abstruse to the due increasing number of components and complicated structure. As a result, the compensator has often been designed without a theoretical analysis and rationale. Furthermore, when integrated boost, buck, or flyback converters inside the IBFC are operated under discontinuous (DCM) or continuous (CCM) conduction

$\dagger$ Corresponding Author: Dept. of Electrical and Biomedical Engineering, Hanyang University, Korea. (rykim@hanyang.ac.kr)

* Dept. of Electrical Engineering, Hanyang University, Korea. (\{cometic, wennirini\}@hanyang.ac.kr)

** Dept. of Mobile Communications Business, Samsung Electronics, Korea. (exkjule@hanyang.ac.kr)

Received: January 28, 2015; Accepted: July 8, 2015

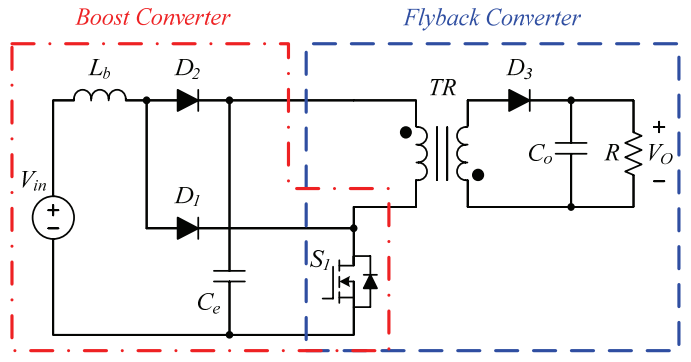

(a) Integrated boost-flyback converter

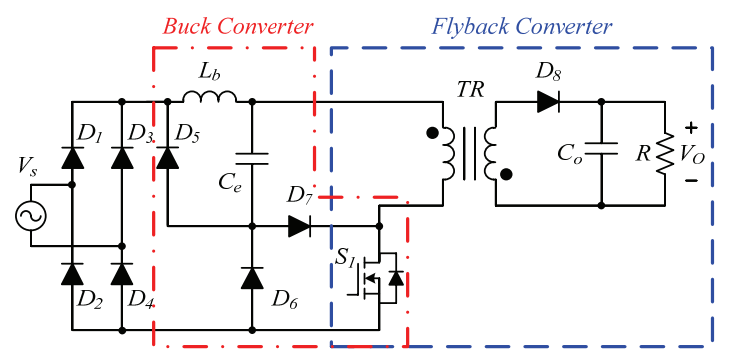

(b) Integrated buck-flyback converter

Fig. 1. Typical examples of the integrated single-stage power converter.

modes, prediction of such dynamic behaviors becomes even more difficult.

Since establishing the average concept to remove the trivial switching effect of a power converter by Middlebrook in 1974, several modeling approaches, including the wellknown state-space averaging method and the averaged switch model, have been proposed for the prediction of converter dynamics [7-13]. These approaches have usually showed effective prediction results for most existing power converters, and thus some papers have explored a direct extension into the IBFC $[14,15]$. However, it exhibits some disadvantages, which include the complexity of the 
circuit operation analysis and the extensive efforts required for mathematical calculation.

As an alternative, the converter-integration approach, which analyzes two internal converters under a standalone operation condition by using the average concept, has been introduced [1, 16], and [17]. These approaches greatly simplify the analysis work, but lack accuracy as they do not account for interactional behaviors. Furthermore, no concrete results supported by a theoretical rationale have been reported. Terminal network approaches, such as the graft scheme and the five-terminal switched transformer average model, have been introduced [18, 19]. These approaches treat the switching element as the port network and incorporate the network parameters to improve prediction accuracy. Compared to the converter-integration approach, however, they require additional consideration for the network parameters and extensive mathematical efforts to satisfy more accurate analysis by increasing the number of terminals.

In this paper, a novel systematic modeling approach that provides accurate dynamics prediction is proposed in order to achieve a theoretical single feedback compensator design for an integrated single-stage power converter. The proposed approach substitutes the internal converter with an equivalent current sinking or sourcing and then combines them to construct a complete dynamic equation using the state-space averaging concept. By using this methodology, the modeling approach becomes straightforward, and the mathematical effort is significantly reduced, while still providing accurate converter behaviors including the interactional dynamics of the internal converters. A detailed modeling procedure is presented, specifically on the target of an integrated boost-flyback converter, as a typical example of an integrated power converter, and a smallsignal model of the full fourth-order system is derived. Based on this derivation, a single feedback compensator is designed with reasonable dynamic response and stability. Several simulation and experiment results, based on a $100 \mathrm{~W}$ integrated boost-flyback converter prototype, are provided in order to verify the accuracy of the proposed approach and its effectiveness.

\section{Interactional Behaviors of the Integrated Power Converter}

The topological incorporation of the integrated single-stage power converter inherently raises problems of complicated dynamics among the internal converters. For a simple explanation, taking the integrated boost-flyback converter (IBoFC) as a convenient example, the instantaneous current waveforms during one switching period, $T_{s}$, are illustrated in Fig. 2. The values $i_{L b}$ and $i_{L m}$ denote the boost and magnetizing inductor currents; $i_{\text {boost }}$ and $i_{\text {flyback }}$ denote the diode $D_{2}$ and the flyback transformer currents; and $i_{c e}$ is the dc-link capacitor current. Note that the waveforms are

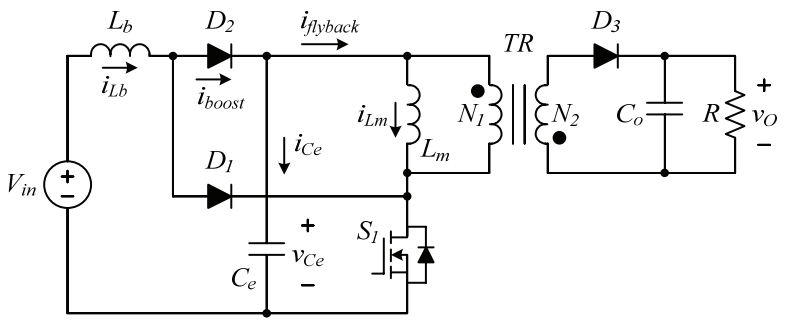

(a) Integrated boost-flyback converter

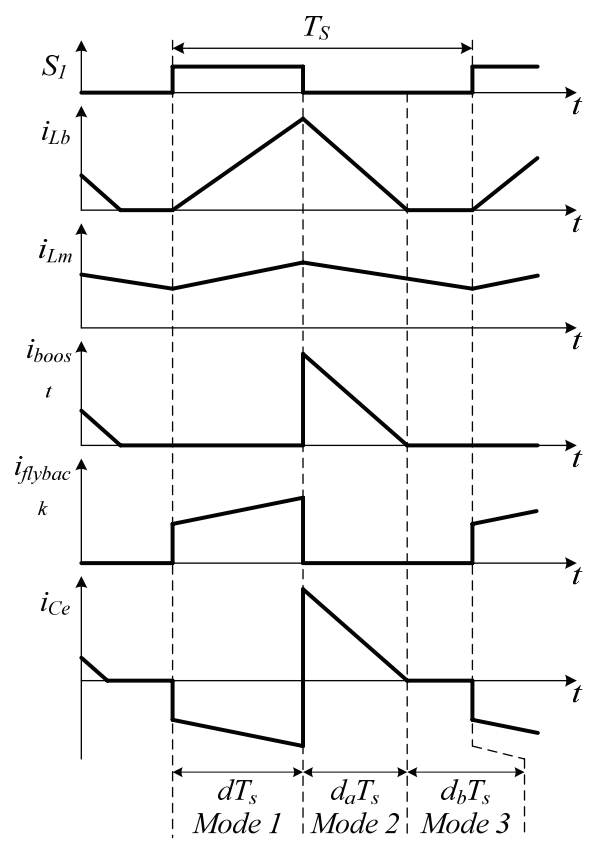

(b) Instantaneous current waveforms

Fig. 2. Integrated boost-flyback converter and theoretical waveforms.

distinguished by three different submodes in one switching period. In mode 1 , the switch $S_{1}$ turns on, and the $i_{L b}$ and the $i_{L m}$ are linearly increased. The $i_{\text {boost }}$ is zero since the diode $D_{2}$ is reverse-biased. The $i_{\text {flyback }}$ is the same as the $i_{L m}$. In mode 2, the switch $S_{1}$ turns off and the diode $D_{2}$ is on. The $i_{L b}$ decreases linearly and flows through diode $D_{2}$. Due to the switch $S_{1}$ being off, the $i_{\text {flyback }}$ becomes zero. Mode 3 starts when the $i_{L b}$ is zero with DCM. The value of $i_{L b}$ and $i_{\text {boost }}$ maintain zero, while $i_{L m}$ flows continuously with CCM.

As illustrated in Fig. 2, the IBoFC operates similar to the standalone boost and flyback converter. However, the $i_{c e}$, which determines the dc-link capacitor voltage, $v_{C e}$, is alternatively governed by the $i_{L b}$ and the $i_{L m}$. Consequently, the $v_{C e}$ varies according to the internal converter operations The overall converter dynamics become complicated due to the interactional behaviors originating from the inside converters.

\section{Novel systematical modeling approach}

As seen from Fig. 2, the total electrical charge, $Q_{c e}$, 
incoming to $C_{e}$ over one switching period is

$$
Q_{c e}=\int_{0}^{T_{s}} i_{c e} d t=\int_{0}^{d T_{s}}\left(-i_{\text {flyback }}\right) d t+\int_{d T_{s}}^{d_{a} T_{s}} i_{\text {boost }} d t
$$

Applying the small ripple approximation under the assumption that the switching ripple is smaller than the dc component, in our case the $i_{L m}$ peak-to-peak ripple percentage is about $28 \%$ based on Eq. (2) and Table 1, where "-" designates the averaged value over one switching period, and taking the average operation over one switching period, the averaged dc-link capacitor voltage, $\bar{U}_{C e}$, is given as Eq. (3).

$$
\begin{gathered}
i_{L m_{-} p p}(\%)=\frac{i_{L m_{-} p p}}{\bar{i}_{L m}} \times 100=\frac{\bar{v}_{C e} V_{o} d(1-d) T_{s}}{L_{m} P_{o} n} \times 100 \\
C_{e} \frac{d \bar{v}_{C e}}{d t}=-\bar{i}_{\text {flyback }}+\bar{i}_{\text {boost }}
\end{gathered}
$$

Eq. (3) indicates that the dc-link capacitor is modeled by the averaged boost diode and the flyback currents, $\bar{l}_{\text {boost }}$ or $\bar{i}_{\text {flyback }}$. Therefore, from the state-space averaging point of view, the internal converters are equivalently approximated as the corresponding current sinking or sourcing as shown in Fig. 3. The modeling equations of the internal converters structures are simply obtained using Kirchhoff's circuit laws and then combined in order to construct the full order modeling equations for the integrated boost-flyback power converter. Such a modeling approach using a current

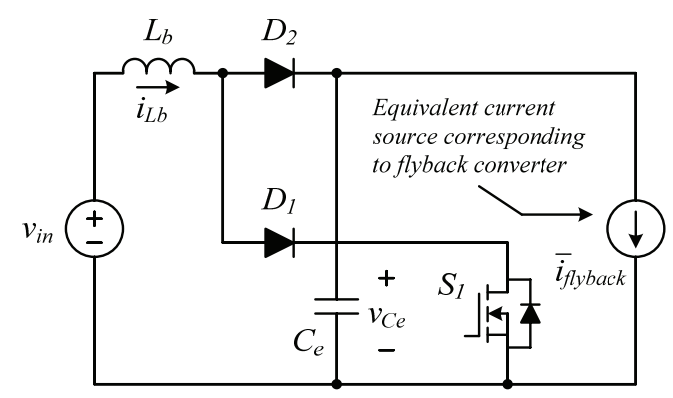

(a) Boost converter with current sink

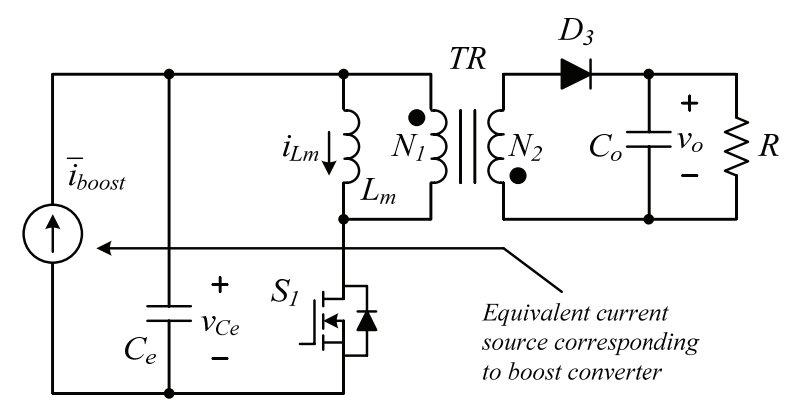

(b) Flyback converter with current source

Fig. 3. Equivalent standalone model of the internal converter with a current source. source significantly simplifies the model effort, while providing a straightforward solution that provides accurate dynamics including interactive behaviors.

\subsection{Detail modeling procedure}

Fig. 4 shows the equivalent standalone model of the internal boost converter and its inductor current under DCM operation. Note that the internal flyback converter is represented by the current sinking.

According to each subinterval, the state equations can be obtained as

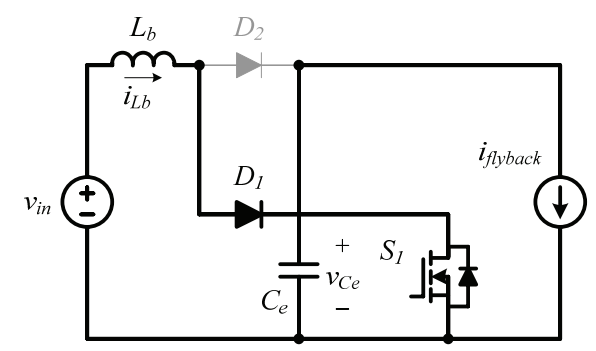

(a) Subinterval 1

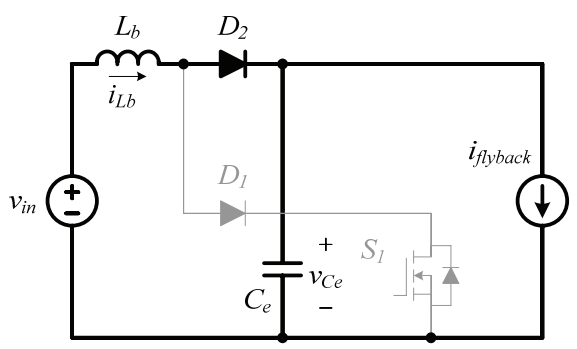

(b) Subinterval 2

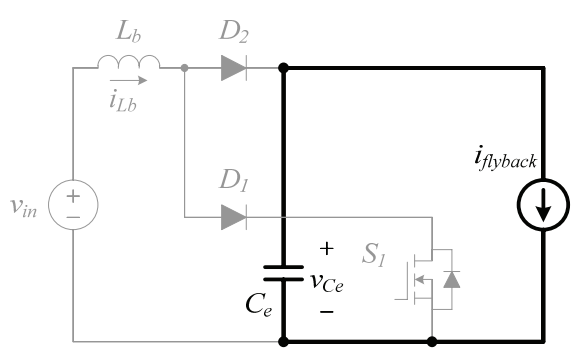

(c) Subinterval 3

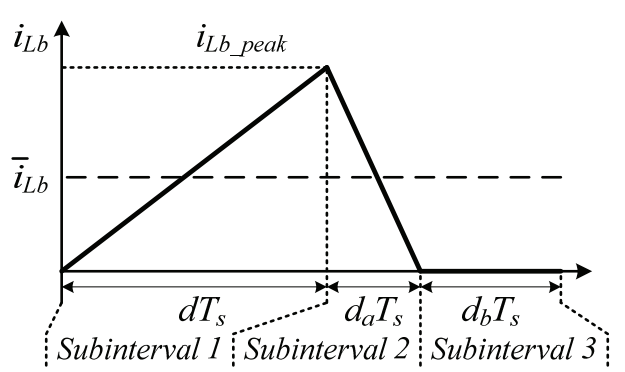

(d) Theoretical waveform of the boost inductor current

Fig. 4. Operational mode of the internal boost converter. 
Subinterval 1
$\begin{cases}L_{b} \frac{d i_{L b}}{d t}=v_{\text {in }} & \text { Subinterval } 2 \\ C_{e} \frac{d v_{C e}}{d t}=-\bar{i}_{\text {flyback }} & \left\{\begin{array}{l}L_{b} \frac{d i_{L b}}{d t}=v_{\text {in }}-v_{C e} \\ C_{e} \frac{d v_{C e}}{d t}=i_{L b}-\bar{i}_{\text {flyback }}\end{array} \text {, and }\right.\end{cases}$

Subinterval 3

$$
\left\{\begin{array}{l}
L_{b} \frac{d i_{L b}}{d t}=0 \\
C_{e} \frac{d v_{C e}}{d t}=-\bar{i}_{\text {flyback }}
\end{array}\right.
$$

From Eq. (4) and Fig. 4(d), the averaged state equations can be obtained as

$$
\begin{aligned}
L_{b} \frac{d i_{L b}}{d t} & =v_{i n} \cdot d+\left(v_{\text {in }}-v_{C e}\right) \cdot d_{a}+0 \cdot d_{b} \\
C_{e} \frac{d v_{C e}}{d t} & =-\bar{i}_{\text {flyback }} \cdot d+\bar{i}_{\text {boost }}-\bar{i}_{\text {flyback }} \cdot d_{a}-\bar{i}_{\text {flyback }} \cdot d_{b}
\end{aligned}
$$

where $\bar{l}_{\text {boost }}$ is used instead of $i_{L b} \cdot d_{a}$ because the small ripple approximation cannot be applied to $i_{L b}$ due to DCM operation.

In Eq. (5), the subinterval time $d_{a}$ and $d_{b}$ and the $\bar{l}_{\text {boost }}$ should be replaced by an expression of the state and input variables. In Fig. $4(\mathrm{~d})$, the maximum value of $i_{L b}\left(i_{L b \_p e a k}\right)$ and the average value of $i_{L b}\left(\bar{l}_{L b}\right)$ are given by

$$
\begin{gathered}
i_{L b_{-} \text {peak }}=\frac{v_{\text {in }} d T_{s}}{L_{b}} \\
\bar{i}_{L b}=\frac{1}{2}\left(d+d_{a}\right) i_{L b_{-} \text {peak }}
\end{gathered}
$$

where $T_{s}$ is the switching period. From Eqs. (6) and (7), the relational expression between $d_{a}$ (or $d_{b}$ ) and $d$ can be obtained as

$$
\begin{aligned}
d_{a} & =\frac{2 \bar{i}_{L b} L_{b} f_{s}}{v_{i n} d}-d=q-d, \\
q & =\frac{2 \bar{i}_{L b} L_{b} f_{s}}{v_{i n} d} \\
d_{b} & =1-\left(d+d_{a}\right)=1-q
\end{aligned}
$$

where $f_{s}$ is the switching frequency $\left(=1 / T_{s}\right)$. Furthermore, the average boost current $\bar{l}_{\text {boost }}$ can be obtained by calculating the triangle area during subinterval 2 in Fig. 4(d).

$$
\bar{i}_{\text {boost }}=\frac{1}{2}(q-d) \frac{v_{\text {in }} d T_{s}}{L_{b}}
$$

From Eqs. (7) and (9), the expression between $\bar{l}_{L b}$ and $\bar{\imath}_{\text {boost }}$ can be obtained as

$$
\bar{i}_{\text {boost }}=\frac{(q-d)}{q} \bar{i}_{L b}
$$

By applying Eqs. (8) and (10) to Eq. (5), the averaged state equations of the boost converter consist only of the state and input variables as

$$
\begin{aligned}
L_{b} \frac{d i_{L b}}{d t} & =v_{i n} \cdot q-v_{C e} \cdot(q-d), \\
C_{e} \frac{d v_{C e}}{d t} & =i_{L b} \cdot \frac{(q-d)}{q}-\bar{i}_{\text {flyback }}
\end{aligned}
$$

Fig. 5 shows the equivalent standalone model of the internal flyback converter and the current waveform. Similarly, the internal boost converter is represented by the current sourcing.

According to each subinterval, the state equations can be obtained as

$$
\begin{aligned}
& \text { Subinterval } 1 \\
& \left\{\begin{array}{ll}
C_{e} \frac{d v_{C e}}{d t}=\bar{i}_{\text {boost }}-i_{L m} \\
L_{m} \frac{d i_{L m}}{d t}=v_{C e} \\
C_{o} \frac{d v_{o}}{d t}=-\frac{v_{o}}{R}
\end{array},\left\{\begin{array}{l}
C_{e} \frac{d v_{C e}}{d t}=\bar{i}_{\text {boost }} \\
L_{m} \frac{d i_{L m}}{d t}=-\frac{v_{o}}{n} \\
C_{o} \frac{d v_{o}}{d t}=\frac{i_{L m}}{n}-\frac{v_{o}}{R}
\end{array}\right.\right.
\end{aligned}
$$

From Eq. (12) and Fig. 5(c), the averaged state equations of the flyback converter are given by

$$
\begin{aligned}
C_{e} \frac{d v_{C e}}{d t} & =\left(\bar{i}_{\text {boost }}-i_{L m}\right) \cdot d+\bar{i}_{\text {boost }} \cdot(1-d) \\
& =\bar{i}_{\text {boost }}-i_{L m} \cdot d, \\
L_{m} \frac{d i_{L m}}{d t} & =v_{C e} \cdot d-\frac{v_{o}}{n} \cdot(1-d) \\
& =v_{C e} \cdot d-v_{o} \cdot \frac{(1-d)}{n}, \\
C_{o} \frac{d v_{o}}{d t} & =-\frac{v_{o}}{R} \cdot d+\left(\frac{i_{L m}}{n}-\frac{v_{o}}{R}\right) \cdot(1-d) \\
& =i_{L m} \cdot \frac{(1-d)}{n}-\frac{v_{o}}{R} .
\end{aligned}
$$

By comparing Eq. (11) and Eq. (13), it can be determined that the analytical expressions of the two equivalent current sources are

$$
\bar{i}_{\text {boost }}=i_{L b} \cdot \frac{(q-d)}{q}, \quad \bar{i}_{\text {flyback }}=i_{L m} \cdot d
$$

Therefore, the complete averaged state equations of the IBoFC are given by Eq. (15) from (11), (13), and (14). 


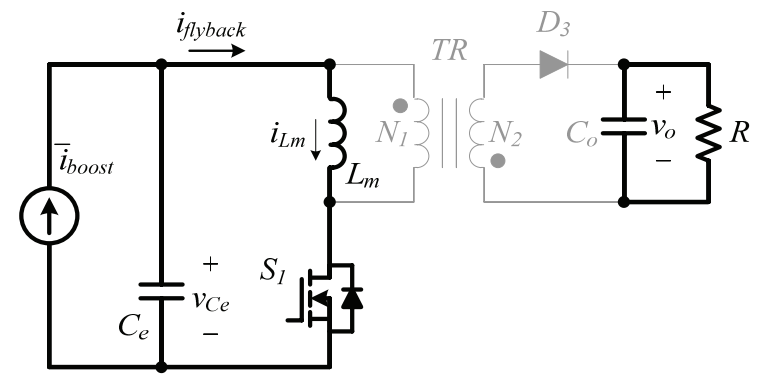

(a) Subinterval 1

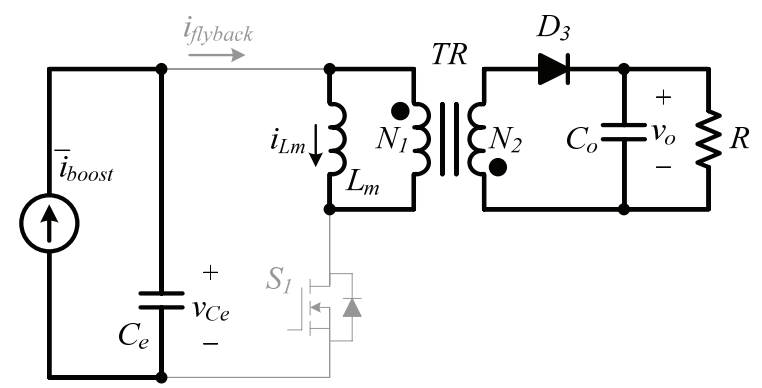

(b) Subinterval 2

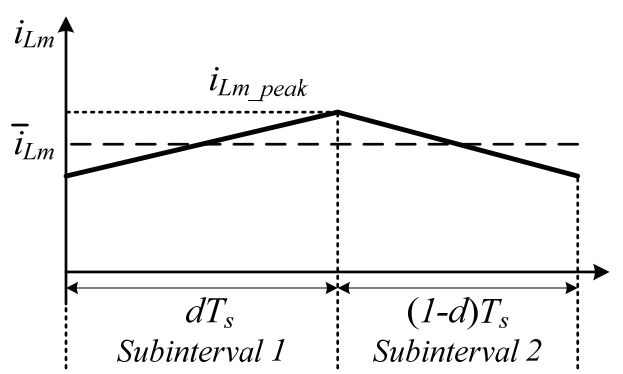

(c) Theoretical waveform of the magnetizing inductor current

Fig. 5. Operational mode of the internal flyback converter.

$$
\frac{d}{d t}\left[\begin{array}{c}
i_{L b} \\
v_{C e} \\
i_{L m} \\
v_{o}
\end{array}\right]=\left[\begin{array}{cccc}
0 & -\frac{q-d}{L_{b}} & 0 & 0 \\
\frac{q-d}{C_{e} \cdot q} & 0 & -\frac{d}{C_{e}} & 0 \\
0 & \frac{d}{L_{m}} & 0 & -\frac{1-d}{L_{m} \cdot n} \\
0 & 0 & \frac{1-d}{C_{o} \cdot n} & -\frac{1}{C_{o} \cdot R}
\end{array}\right]\left[\begin{array}{c}
i_{L b} \\
v_{C e} \\
i_{L m} \\
v_{o}
\end{array}\right]+\left[\begin{array}{c}
\frac{q}{L_{b}} \\
0 \\
0 \\
0
\end{array}\right] v_{i n}
$$

The IBoFC modeling and analysis are significantly simplified using the proposed approach while providing a straightforward solution that agrees with the conventional direct modeling.

Subsequently, the perturbed expressions such as Eq. (16) are applied to Eq. (15), where $X\left(=I_{L b}, V_{C e}, I_{L m}\right.$ and $\left.V_{o}\right)$ is the dc quiescent value and $\hat{x}\left(=\hat{i}_{L b}, \hat{v}_{C e}, \hat{i}_{L m}\right.$ and $\left.\hat{v}_{o}\right)$ is the small ac variation as follows:

$$
\left[\begin{array}{c}
i_{L b} \\
v_{C e} \\
i_{L m} \\
v_{o}
\end{array}\right]=\left[\begin{array}{c}
I_{L b} \\
V_{C e} \\
I_{L m} \\
V_{o}
\end{array}\right]+\left[\begin{array}{c}
\hat{i}_{L b} \\
\hat{v}_{C e} \\
\hat{i}_{L m} \\
\hat{v}_{o}
\end{array}\right], \quad \begin{aligned}
& \quad d=D+\hat{d} \\
& \quad
\end{aligned}
$$

If the second-order ac terms are neglected from the resultant equations, the dc terms and first-order ac terms remain. The resultant first-order ac terms that correspond to the small-signal ac model are given by Eq. (17), where $\hat{\imath}_{o}$ is the ac variation component of the load current.

$$
\begin{aligned}
& \frac{d}{d t}\left[\begin{array}{c}
\hat{i}_{L b} \\
\hat{v}_{C e} \\
\hat{i}_{L m} \\
\hat{v}_{o}
\end{array}\right]=\left[\begin{array}{cccc}
\frac{k\left(V_{i n}-V_{C e}\right)}{L_{b}} \frac{D-k I_{L b}}{L_{b}} & 0 & 0 \\
\frac{1}{C_{e}} & 0 & -\frac{D}{C_{e}} & 0 \\
0 & \frac{D}{L_{m}} & 0 & -\frac{1-D}{L_{m} \cdot n}
\end{array}\right]\left[\begin{array}{c}
\hat{i}_{L b} \\
\hat{v}_{C e} \\
\hat{i}_{L m} \\
\hat{v}_{o}
\end{array}\right] \\
& \left.0 \quad 0 \quad \frac{1-D}{C_{o} \cdot n}-\frac{1}{C_{o} \cdot R}\right] \\
& {\left[\begin{array}{ccc}
\frac{k I_{L b}}{L_{b} D}\left(V_{C e}-V_{i n}+\frac{D V_{C e}}{k I_{L b}}\right) & \frac{k I_{L b}}{L_{b}} & 0 \\
-\frac{1}{C_{e}}\left(I_{L m}+\frac{2}{k}\right) & 0 & 0 \\
\frac{1}{L_{m}}\left(V_{C e}+\frac{V_{o}}{n}\right) & 0 & 0 \\
-\frac{I_{L m}}{C_{o} \cdot n} & 0 & -1
\end{array}\right]\left[\begin{array}{c}
\hat{d} \\
\hat{v}_{i n} \\
\hat{i}_{o}
\end{array}\right],} \\
& k=\frac{2 L_{b} f_{s}}{D v_{\text {in }}}
\end{aligned}
$$

Furthermore, based on the resultant dc terms and the parameter values in Table 1 , the equilibrium dc values are obtained as $I_{L b}=3.333 \mathrm{~A}, V_{C e}=58.904 \mathrm{~V}, I_{L m}=4.198 \mathrm{~A}$, and $D=0.404$. These test conditions shown in Table 1 were chosen to implement a high step-up dc-dc converter which is required in recent distributed generation systems, with a low input voltage [20-24].

Fig. 6 shows the Bode plot of the control-to-output transfer function $\left(G_{v d}=\hat{v}_{o} / \hat{d}\right)$ and the output impedance $\left(Z_{\text {out }}=\hat{v}_{o} / \hat{\imath}_{o}\right)$.

Table 1. Test conditions

\begin{tabular}{c|c}
\hline Output Power $\left(P_{o}\right)$ & $100 \mathrm{~W}$ \\
\hline Input Voltage $\left(V_{i n}\right)$ & $30 \mathrm{~V}$ \\
\hline Output Voltage $\left(V_{o}\right)$ & $200 \mathrm{~V}$ \\
\hline Switching Frequency $\left(f_{s}\right)$ & $100 \mathrm{kHz}$ \\
\hline Boost Inductor $\left(L_{b}\right)$ & $15 \mu \mathrm{H}$ \\
\hline Magnetizing inductor $\left(L_{m}\right)$ & $200 \mu \mathrm{H}$ \\
\hline DC-link Capacitor $\left(C_{e}\right)$ & $4.4 \mu \mathrm{F}$ \\
\hline Output Capacitor $\left(C_{o}\right)$ & $440 \mu \mathrm{F}$ \\
\hline Transformer turns ratio $(n)$ & 5 \\
\hline
\end{tabular}




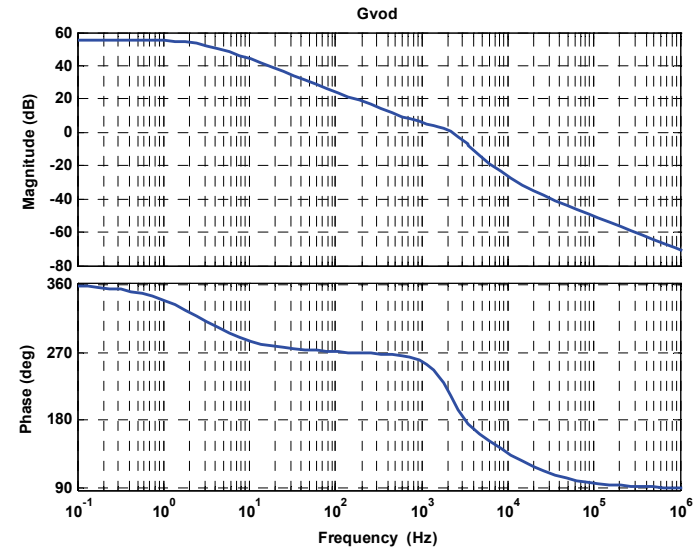

(a) Control-to-output transfer function $\left(G_{v d}\right)$

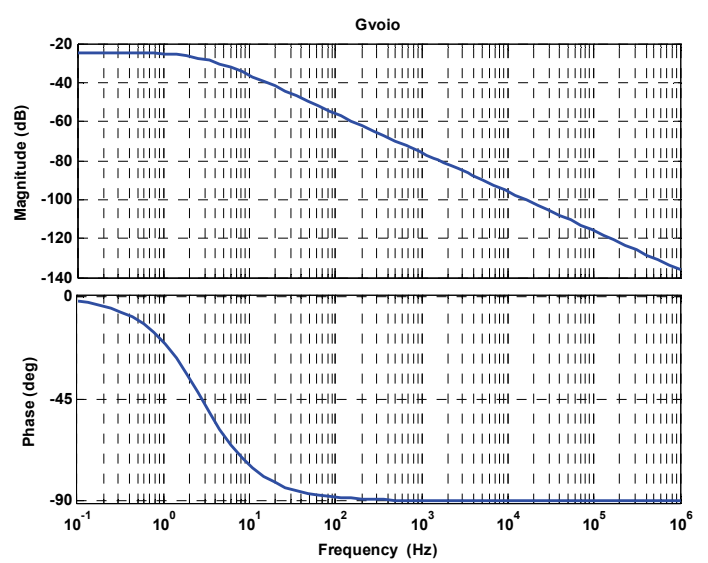

(b) Output impedance $\left(Z_{\text {out }}\right)$

Fig. 6. Bode plot of the open-loop transfer function.

In the previous literature [14], the direct extension approach of the conventional state-space averaging method is applied to obtain the dynamic model of a single-stage single-switch (S4) parallel boost-flyback-flyback converter. The average state variable description of the converter is derived at first. However, some inductor currents of total five energy storage elements aren't selected as state variables since those inductor currents operate in DCM. Furthermore, during final small-signal model derivation, one capacitor voltage is considered as a constant value and omitted from the vector of state variables to simplify the procedure since this variable is just an interactional dynamic. Therefore, the complete dynamic model isn't achieved. Moreover, the validation of the derived model is verified only in the time domain, not the frequency domain.

However, the proposed approach in this paper achieves a straightforward solution by using reduced state variables and combining simply resultant equations, while providing accurate converter behaviors including interactional dynamics of the internal converters.

\subsection{Single loop compensator design}

Fig. 7 shows a block diagram of the output voltage

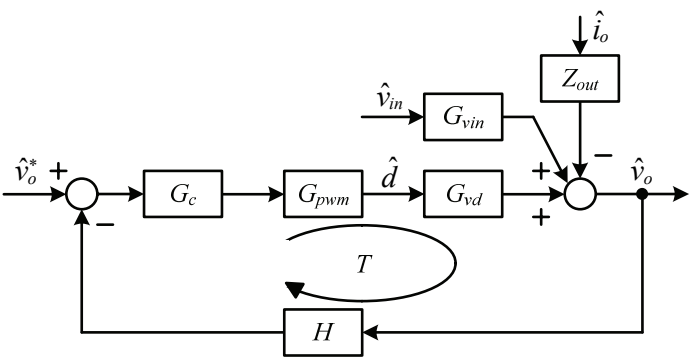

Fig. 7. Block diagram of the output voltage control.

control based on the small-signal model, and Eq. (18) is the analytical expression for the output voltage. $G_{\text {vin }}\left(=\hat{v}_{o} / \hat{v}_{\text {in }}\right)$ is the line-to-output transfer function, $G_{p w m}$ is the pulse-width modulator gain, $G_{c}$ is the voltage compensator, $H$ is the sensor gain, and $T$ is the loop gain.

$$
\begin{gathered}
\hat{v}_{o}=\hat{v}_{o}^{*} \frac{1}{H} \frac{T}{1+T}+\hat{v}_{\text {in }} \frac{G_{v i n}}{1+T}-\hat{i}_{o} \frac{Z_{\text {out }}}{1+T}, \\
T=G_{c} G_{p w m} G_{v d} H
\end{gathered}
$$

For voltage regulation, a proportional-integral (PI) compensator is designed based on the control-to-output transfer function. A typical PI compensator can be adopted with the following design process:

1) place one pole to eliminate the steady-state error (integrator);

2) place one zero in the low frequency region (at $10 \mathrm{~Hz}$ ) to secure the phase margin in front of the resonant frequency $(2.24 \mathrm{kHz})$;

3) locate the crossover frequency approximately one decade less than the resonant frequency (at $100 \mathrm{~Hz}$ );

4) determine the dc gain. By using this process, the 100 $\mathrm{Hz}$ bandwidth and the $85^{\circ}$ phase margin are secured, and the resultant PI compensator is

$$
G_{c}=k \frac{1+s / \omega_{z}}{s}, \quad\left(k=4.0192, \omega_{z}=2 \pi \cdot 10\right)
$$

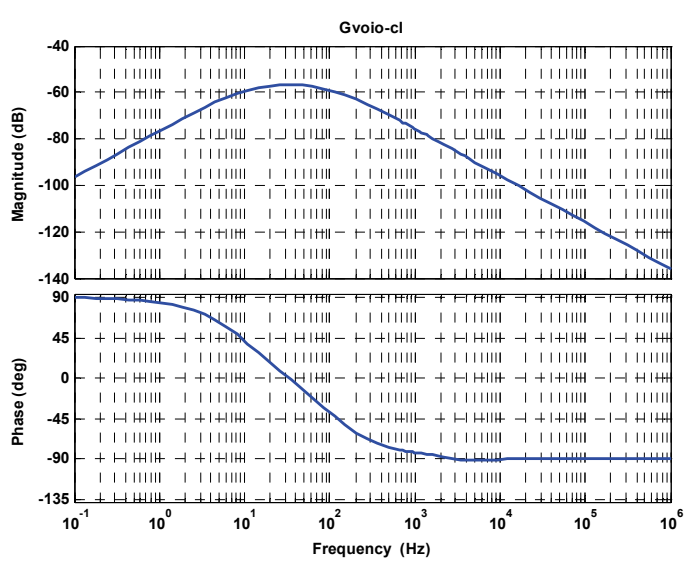

Fig. 8. Bode plot of the closed-loop output impedance transfer function. 
Furthermore, by ascertaining that all roots of the characteristic equation lie in the left-hand $s$-plane for the $1+T$, it achieves the complete stable time response. Fig. 8 shows the Bode plot of the closed-loop output impedance which is more damped than in the case of the open-loop in Fig. 6 (b).

\section{Novel Systematical Modeling Approach}

To confirm the effectiveness of the proposed approach to IBoFC modeling, a Bode plot of the control-to-output transfer function was obtained using a schematic-based PSIM simulation tool. The test conditions are summarized in Table 1. By comparing the simulation and the theoretical waveforms in Fig. 9, it becomes apparent that the frequency response plots are almost identical. It should be noted that the unexpected change above $100 \mathrm{kHz}$ is caused by the switching frequency in the simulation setting.

To verify the theoretical operation and evaluate the performance of the proposed converter, a $100 \mathrm{~W}$ IBoFC prototype was designed. An IRFB4227PbF MOSFET $\left(V_{D S}=200 \mathrm{~V}, I_{D} @ 25^{\circ} \mathrm{C}=65 \mathrm{~A}, R_{D S(O N)}=19.7 \mathrm{~m} \Omega\right)$ from IR was used for the main switch $\left(S_{l}\right)$, UH10FT diodes $\left(V_{R R M}=\right.$ $300 \mathrm{~V}, I_{F}=10 \mathrm{~A}, t_{r r}=25 \mathrm{~ns}$ ) from VISHAY were used for the diodes $\left(D_{l}, D_{2}\right)$, and an IDH02SG120 SiC diode $\left(V_{R R M}=\right.$ $1200 \mathrm{~V}, I_{F}=2 \mathrm{~A}$ ) from Infineon was used for the diode $\left(D_{3}\right)$. For the transformer, a pair of ferrite cores (TDK,

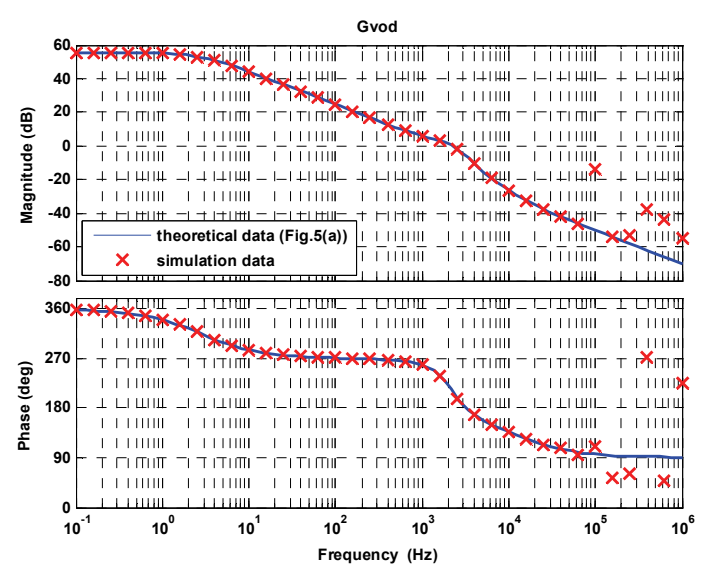

Fig. 9. Bode plot of the control-to-output transfer function by simulation.

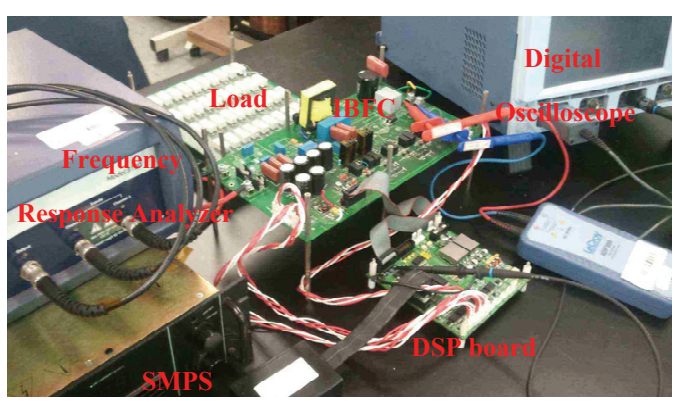

Fig. 10. Photograph of the experimental setup.
PC40EER40) was used, and 25 turns and 125 turns were wound for $N_{1}$ and $N_{2}$, respectively. Fig. 10 shows a photograph of the experimental setup, and the other experimental conditions are the same as in Table 1.

Fig. 11 shows the experimental frequency response of the IBoFC obtained using a Frequency Response Analyzer (Venable model 3120). The experimental result matches closely with the theoretical frequency response in Fig. 9 in the low frequency region under $1 \mathrm{kHz}$, while it shows a different trend in the high frequency region over $1 \mathrm{kHz}$ due to the equivalent series resistance of the output electrolytic capacitor $\left(C_{o}\right)$. Since the primary concern for the relevant controller design is the low frequency region and the designed system bandwidth is $100 \mathrm{~Hz}$, the difference in the high frequency region is not critical.

Fig. 12 shows the operational waveforms of the IBoFC at full load conditions. It can be seen that the boost inductor current flows in the DCM.

Fig. 13 shows the load current $\left(i_{o}\right)$ and the output voltage $\left(v_{o}\right)$ waveforms according to the load variation. It shows a stable output voltage in spite of the load variation.

\section{Conclusion}

This paper proposed a novel systematic modeling

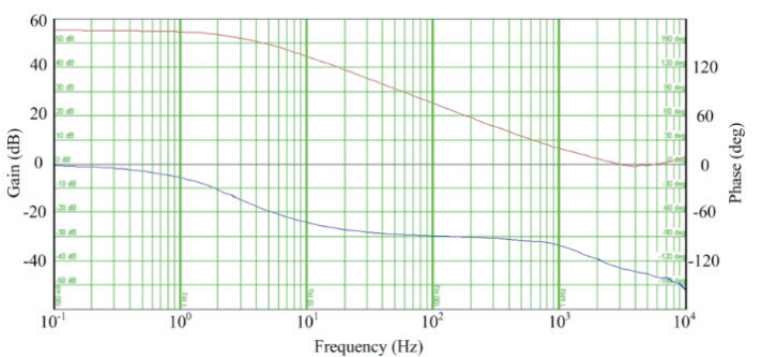

Fig. 11. Experimental frequency response of the IBoFC by FRA (Venable model 3120).

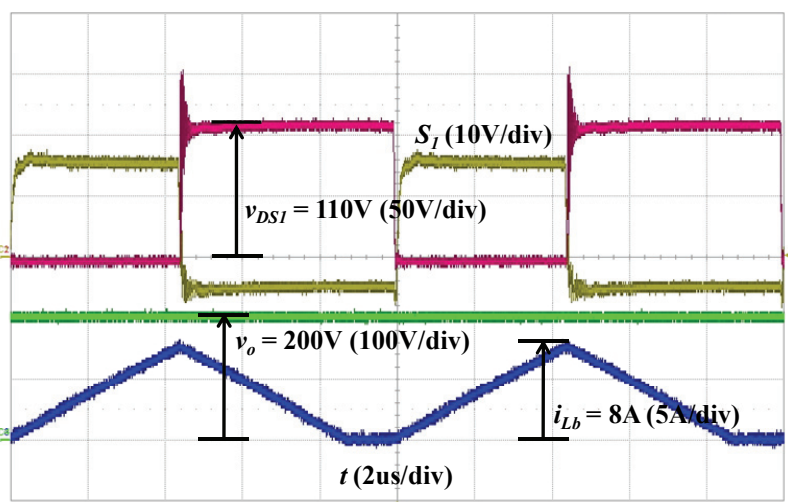

Fig. 12. Gate-to-source voltage waveform of the main switch $\left(S_{I}\right)$, drain-to-source voltage waveform of $S_{I}\left(v_{D S I}\right)$, output voltage waveform $\left(v_{O}\right)$, and boost inductor current waveform $\left(i_{L b}\right)$ at $100 \%$ load. 


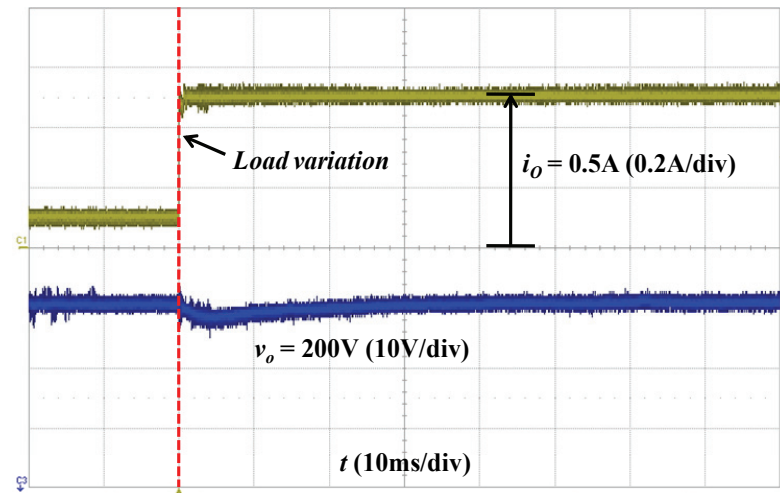

(a) Load change from $100 \%$ to $20 \%$

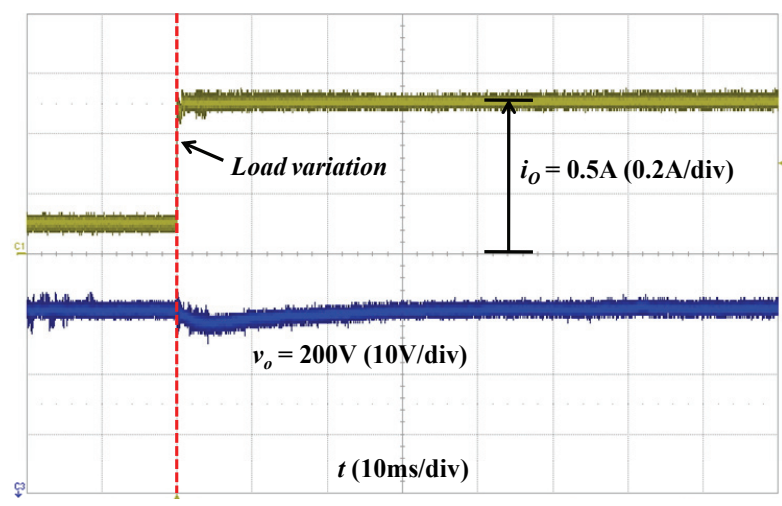

(b) Load change from $20 \%$ to $100 \%$

Fig. 13. Load variation waveforms.

approach of the integrated single-stage power converter for dynamic analysis. A detailed modeling procedure was presented, specifically on a target of the IBoFC, as a typical example of the integrated power converter. The proposed approach simplifies the mathematical process of IBoFC modeling and provides straightforward fullorder dynamic equations. The simulation and experimental results show the validity of the systematic modeling approach and the effectiveness of the voltage control based on the derived model.

\section{Acknowledgements}

This work was supported by the research fund of Hanyang University (HY-2013).

\section{References}

[1] J. M. Alonso, M. A. Dalla Costa, and C. Ordiz, "Integrated Buck-Flyback Converter as a HighPower-Factor Off-Line Power Supply," Industrial Electronics, IEEE Transactions on, vol. 55, no. 3, pp. 1090-1100, Mar. 2008.
[2] M. A. Dalla Costa, T. B. Marchesan, J. S. da Silveira, A. R. Seidel, R. Nederson do Prado, and J. M. Alonso Alvarez, "Integrated Power Topologies to Supply HPS Lamps: A Comparative Study," Power Electronics, IEEE Transactions on, vol. 25, no. 8, pp. 2124-2132, Aug. 2010.

[3] L. Yan-Cun, and C.-L. Chen, "A Novel Single-Stage High-Power-Factor AC-to-DC LED Driving Circuit With Leakage Inductance Energy Recycling," Industrial Electronics, IEEE Transactions on, vol. 59, no. 2, pp. 793-802, Feb. 2012.

[4] B. Singh, V. Bist, "Improved power quality IHQRRBIFRED converter fed BLDC motor drive," Journal of Power Electronics, vol. 13, no. 2, pp. 256-263, March. 2013.

[5] Q. Chongming, and K. M. Smedley, "A topology survey of single-stage power factor corrector with a boost type input-current-shaper," Power Electronics, IEEE Transactions on, vol. 16, no. 3, pp. 360-368, May. 2001.

[6] R. Redl, L. Balogh, and N. O. Sokal, "A new family of single-stage isolated power-factor correctors with fast regulation of the output voltage," in Proc. PESC, vol. 2, pp. 1137-1144, 1994.

[7] S. Cuk, and R. D. Middlebrook, "A general unified approach to modelling switching DC-to-DC converters in discontinuous conduction mode," in Proc. PESC, pp. 36-57, 1997.

[8] R. W. Erickson, and D. Maksimović, Fundamentals of Power Electronics 2nd Ed. Springer Science \& Business Media, pp. 63-330, 2011.

[9] D. Maksimović, and S. Cuk, "A unified analysis of PWM converters in discontinuous modes," Power Electronics, IEEE Transactions on, vol. 6, no. 3, pp. 476-490, Jul. 1991.

[10] S. Jian, D. M. Mitchell, M. F. Greuel, P. T. Krein, and R. M. Bass, "Averaged modeling of PWM converters operating in discontinuous conduction mode," Power Electronics, IEEE Transactions on, vol. 16, no. 4, pp. 482-492, Jul. 2001.

[11] V. Vorperian, "Simplified analysis of PWM converters using model of PWM switch. Continuous conduction mode," Aerospace and Electronic Systems, IEEE Transactions on, vol. 26, no. 3, pp. 490-496, May. 1990.

[12] V. Vorperian, "Simplified analysis of PWM converters using model of PWM switch. II. Discontinuous conduction mode," Aerospace and Electronic Systems, IEEE Transactions on, vol. 26, no. 3, pp. 497-505, May. 1990.

[13] F. Wang, X. Ma, "Modeling and Analysis of Fractional Order Buck Converter in DCM Operation by Fractional Calculus and the Circuit-Averaging Technique," Journal of Power Electronics, vol. 13, no. 6, pp.1008-1015, Nov. 2013.

[14] L. Heng-Yi, and C. Hung-Chi, "Dynamic Modeling 
and Controller Design for a Single-Stage SingleSwitch Parallel Boost-Flyback-Flyback Converter," Power Electronics, IEEE Transactions on, vol. 27, no. 2, pp. 816-827, Feb. 2012.

[15] T. J. Liang, and K. C. Tseng, "Analysis of integrated boost-flyback step-up converter," Electric Power Applications, IEE Proceedings, vol. 152, no. 2, pp. 217-225, Mar. 2005.

[16] D. Gacio, J. M. Alonso, A. J. Calleja, J. Garcia, and M. Rico-Secades, "A Universal-Input Single-Stage High-Power-Factor Power Supply for HB-LEDs Based on Integrated Buck-Flyback Converter," Industrial Electronics, IEEE Transactions on, vol. 58, no. 2, pp. 589-599, Feb. 2011.

[17] W. Tsai-Fu, L. Sihh-An, and C. Yu-Kai, "High-powerfactor single-stage converter with robust controller for universal off-line applications," Power Electronics, IEEE Transactions on, vol. 14, no. 6, pp. 1078-1085, Nov. 1999.

[18] W. Tsai-Fu, and C. Yu-Kai, "Modeling of single-stage converters with high power factor and fast regulation," Industrial Electronics, IEEE Transactions on, vol. 46, no. 3, pp. 585-593, Jun. 1999.

[19] K. Rustom, Q. Weihong, C. Iannello, and I. Batarseh, "Five-Terminal Switched Transformer Average Modeling and AC Analysis of PFC Converters," Power Electronics, IEEE Transactions on, vol. 22, no. 6, pp. 2352-2362, Nov. 2007.

[20] S. B. Kjaer, J. K. Pedersen, and F. Blaabjerg, "A review of single-phase grid-connected inverters for photovoltaic modules," Industry Applications, IEEE Transactions on, vol. 41, no. 5, pp. 1292-1306, Sept.Oct. 2005.

[21] L. Wuhua, and H. Xiangning, "Review of Nonisolated High-Step-Up DC/DC Converters in Photovoltaic Grid-Connected Applications," Industrial Electronics, IEEE Transactions on, vol. 58, no. 4, pp. 1239-1250, April. 2011.

[22] J.-I. Kang, S.-K. Han, J. Han, "Lossless Snubber with Minimum Voltage Stress for Continuous Current Mode Tapped-Inductor Boost Converters for High Step-up Applications," Journal of Power Electronics, vol. 14, no. 4, pp. 621-631, Jul. 2014

[23] Q. Luo, Y. Zhang, P. Sun, L. Zhou, "An Active Clamp High Step-Up Boost Converter with a Coupled Inductor," Journal of Power Electronics, vol. 15, no. 1, pp. 86-95, Jan. 2015.

[24] L. He, T. Zeng, T. Li, Y. Liao, W. Zhou, "High Stepup Active-Clamp Converter with an Input Current Doubler and Symmetrical Switched-Capacitor Circuit," Journal of Power Electronics, vol. 15, no. 3, pp. 587601, May. 2015.

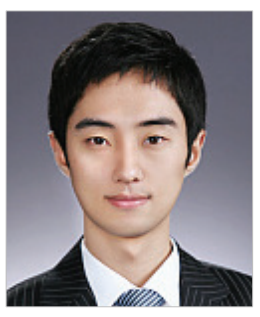

Ki-Young Choi He received the B.S. degree in electrical engineering from Hanyang University, Seoul, Korea, in 2011, where he is currently working toward the direct Ph.D. degree. His current research interests include power quality and power converter system for renewable energies.

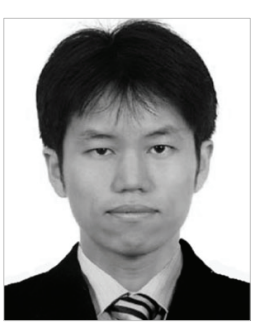

Kui-Jun Lee He received the B.S. and $\mathrm{Ph} . \mathrm{D}$. degrees in electrical engineering from Hanyang University, Seoul, Korea, in 2005 and 2012, respectively. From 2012 to 2014, he was a Postdoctoral Researcher at FREEDM Systems Center, North Carolina State University, Raleigh. Since 2014, he has been with Samsung Electronics, Suwon, Korea, where he is currently a Senior Engineer. His research interests include power converter system for renewable energies and soft switching techniques.

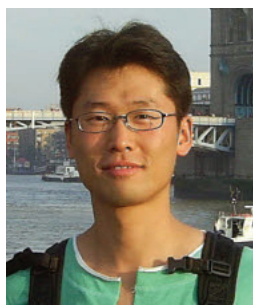

Yong-Wook Kim He received B.S and M.S degrees form Hanyang University, Ansan, Korea, in 2002 and 2004, respectively, and $\mathrm{Ph} . \mathrm{D}$. degree in the electrical and biomedical Engineering, Hanyang University, Seoul, Korea, in 2015. Since 2004, he has been a Senior Engineer with the R\&D Team, Digital Appliances, Samsung Electronics, Suwon, Korea. His research interests include power factor correction and softswitching techniques for home appliance systems.

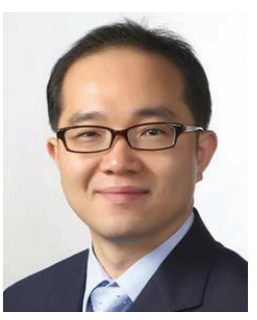

Rae-Young Kim He received B.S and M.S degree from Hanyang University, Seoul, Korea, in 1997 and 1999, respectively, and Ph.D. degree from Virginia Polytechnic Institute and State University, Blacksburg, VA, USA, in 2009, all in electrical engineering. From 1999 to 2004, he was a Senior Researcher at Hyosung Heavy Industry R\&D Center, Seoul. In 2009, he was a Postdoctoral Researcher at National Semiconductor Corporation, working on a smart home energy management system. Since 2010, he has been with Hanyang University, where he is currently an Assistant Professor in the Dep. of Electrical and Biomedical Engineering. His research interests include soft-switching technique, modeling and control of power converter for renewable energy and micro grid, and senseless motor drive. Dr. Kim is a member of the IEEE Power Electronics and Industrial Electronics Societies. He is also a member of the Korean Institute of Power Electronics and Korean Institute of Electrical Engineers. He was a recipient of the 2007 First Prize Paper Award from the IEEE IAS. 